\title{
ASSOCIATION BETWEEN SELF ESTEEM AND ANXIETY LEVELS IN HIGH-RISK PREGNANT WOMEN IN A REFERENCE MATERNITY HOSPITAL IN THE CITY OF RECIFE, PERNAMBUCO, BRAZIL
}

\section{1 *Liniker Scolfild Rodrigues da Silva, ${ }^{2}$ Eliana Lessa Cordeiro, ${ }^{3}$ Cristina Albuquerque Douberin, ${ }^{4}$ Iara Alves Feitoza de Andrade, ${ }^{5}$ Fernanda da Mata Vasconcelos Silva, ${ }^{6}$ Clarissa Silva Pimenta, ${ }^{7}$ Simone Souza de Freitas, ${ }^{8} \mathrm{Joel}$ Azevedo de Menezes Neto, ${ }^{9}$ Fernanda Barbosa dos Santos, ${ }^{10} \mathrm{Ana}$ Paula Maurício da Silva, ${ }^{11}$ Luciana Maria Gomes Davi and ${ }^{12}$ Andrea Cristina Maria da Silva}

1Specialist in Obstetric Nursing in the Residency modality from the Nossa Senhora das Graças College (FENSG)/University of Pernambuco (UPE). Public Health Officer from the Medical Sciences College (FCM)/UPE. Recife, Pernambuco (PE), Brazil. ${ }^{2} \mathrm{MSc}$ in Neuropsychiatry and Behavioral Sciences from the Federal University of Pernambuco (UFPE). Recife, Pernambuco

(PE), Brazil. ${ }^{3} \mathrm{MSc}$ in Nursing from the University of Pernambuco/State University of Paraíba (UPE/UEPB). Campina

Grande, Paraíba (PB), Brazil. ${ }^{4}$ MSc in Nursing from the Federal University of Pernambuco (UFPE). Recife, Pernambuco (PE),

Brazil. ${ }^{5}$ Nursing Doctorate's Student from the University of Pernambuco (UPE). Recife, Pernambuco (PE), Brazil.

${ }^{6}$ Nurse, Specialist in Mental Health in the Residency modality from the Raul Soares Institute (IRS). Minas Gerais, Belo Horizontes (BH), Brazil. ${ }^{7}$ Specialist in Public Health and Family Health Program (FHP) for Nurses from the Futura College. Recife, Pernambuco (PE), Brazil. ${ }^{8}$ Specialist in Higher Education Teaching from the Maurício de Nassau University Center (UNINASSAU). Recife, Pernambuco (PE), Brazil. ${ }^{9}$ Specialist in Emergency and Intensive Care Unit (ICU) from the Higher Education Foundation of Olinda (FUNESO). Recife, Pernambuco (PE), Brazil. ${ }^{10}$ Bacharelor in Nursing from the Maurício de Nassau University Center (UNINASSAU). Recife, Pernambuco (PE), Brazil. ${ }^{11}$ Specialist in Public Health from the Unyleya College. Recife, Pernambuco (PE), Brazil. ${ }^{12}$ Specialist in Family Health from the Higher Education Institute of Santa Catarina (IESC). Recife, Pernambuco (PE), Brazil.

\section{ARTICLE INFO}

Article History:

Received $07^{\text {th }}$ March, 2020

Received in revised form

$26^{\text {th }}$ April, 2020

Accepted $08^{\text {th }}$ May, 2020

Published online $25^{\text {th }}$ June, 2020

\section{Key words:}

Self-Concept; Anxiety; Pregnancy; HighRisk Pregnancy; Comprehensive Health

Care; Women's Health Care.

*Corresponding author:

Liniker Scolfild Rodrigues da Silva,

\begin{abstract}
Objective: To evaluate the association between self-esteem and anxiety in pregnant women admitted to a high-risk sector. Methods: Quantitative, cross-sectional, observational study. Data were collected through interviews with pregnant women admitted to the high-risk maternity ward, from April 1 to June 31, 2016. The sample totaled 112 women and was by convenience. Results: Of the women, $72.3 \%$ presented low self-esteem and significant correlation with educational level $(\mathrm{p}=0.004)$. The anxiety was $60.7 \%$ and the religion was the only variable with a significant association $(p=0.04)$. There was no significant association $(p>0.05)$ between the pattern of selfesteem and levels of anxiety for the fixed margin of error $(5 \%)$. Conclusion: The impaired selfesteem was present in most of the women in this study, especially with low level of schooling. The anxiety was present in the majority of women, and there was an association between it and lack of religious practices. In this study, there was no significant correlation between self-esteem and anxiety. There is need to consider the two cases separately for a complete women's health promotion practice.
\end{abstract}

Copyright (C) 2020, Liniker Scolfild Rodrigues da Silva et al. This is an open access article distributed under the Creative Commons Attribution License, which permits unrestricted use, distribution, and reproduction in any medium, provided the original work is properly cited.

Citation: Liniker Scolfild Rodrigues da Silva, Eliana Lessa Cordeiro, Cristina Albuquerque Douberin et al. "Association between self esteem and anxiety levels in high-risk pregnant women in a reference maternity hospital in the city of recife, pernambuco, Brazil”, International Journal of Development Research, 10, 06, 36568-36573.

\section{INTRODUCTION}

Pregnancy involves numerous physical, hormonal, psychological and social changes, which may reflect, directly, in self-esteem and self-perception of the woman, in the interaction between mother and child, the relations of the woman with her relatives and with her spouse (Osorio-Castaño et al., 2017). Among the changes present in the pregnancypuerperal cycle, the psychological ones deserve notoriety since 
they determine a good evolution in pregnancy. Among the disorders triggered in pregnant women, the Common Mental Disorder (CMD) presents a prevalence of $29.2 \%$ and is characterized by somatic symptoms of depression, irritability, forgetfulness, reduced ability of concentration, anxiety, fatigue, insomnia, difficulty in memory and concentration and complaints. It manifests as a mixture of somatic, anxious and depressive symptoms (Parreira et al., 2017).Anxiety, in the gestational period, has been associated with several reasons, such as fetal distress, preterm birth, low birth weight and problems in the child's development. Other factors also corroborate, such as: demographic data (race, age, marital status, years of study, professional status, socioeconomic level), obstetric, psychological (woman's personal history, psychopathological history, personality characteristics, sexuality and desire to become pregnant), psychosocial (occurrence of significant life events and social support networks) and even cultural factors (Castro et al., 2017). Pregnancy also interferes in the woman's self-esteem due to physical and emotional vulnerability that results from various physiological and anatomical changes that occur throughout the pregnancy cycle (Osorio-Castaño et al., 2017). Self-esteem is the concept a person's has of him/herself, formed during the first childhood, through emotional experiences lived during this period. Over the years, this self-esteem formed has a great importance in the formation of personal relationships, including the establishment of the mother-child bond (Goyatá et al., 2016). Considering the above, the study aims to identify the pattern of self-esteem and anxiety in pregnant women hospitalized in a high risk sector and assess its relations with the sociodemographic variables and the association between self-esteem and anxiety.

\section{METHODS}

Cross-sectional, quantitative study, carried out in the maternity ward of a public hospital in the city of Recife, Pernambuco, Brazil. This institution is a reference in high-risk pregnant women's health care. The study was approved by the Research Ethics Committee (REC) of the Agamenon Magalhães Hospital (HAM) under the CAAE n.: 53579916.2.0000.5197 and opinion n.: 2.710.417. The participants received information on the protocol of the study and signed the Informed Consent Form (ICF). This study is part of the residency completion work (RCW) of the author: Liniker Scolfild Rodrigues da Silva. The data collection occurred through interviews with pregnant women admitted to the highrisk maternity ward in the period from April 1 to June 31, 2016. The sample included pregnant women aged 18 years and excluded: pregnant women suffering from some previous mental disorder and/or with hearing disabilities and illiterate pregnant women. The sample totaled 112 women and constitutes a convenience sample. The pregnant women were approached after admission to the high-risk sector. For the collection of demographic, clinical and obstetric data, a questionnaire was used, adapted to the population under study, which included the following data: age, marital status, education, socioeconomic, housing, dwelling, occupation, religion, gestational age, number of pregnancies, delivery route of previous pregnancies, if the pregnancy was desired and/or planned and reason for hospitalization in high risk. To evaluate the self-esteem, the Rosenberg's Self-Esteem Scale - RSES (1965) was used. This is internationally known and validated in 1989 and adapted to Brazil by Hutz in the year 2000 and aims to identify changes in self-esteem (Cogollo et al. 2015).
This scale is composed of 10 multiple-choice questions, with six related to "oneself", and four related to a "self-deprecating" view. The items are assessed on a Likert-type scale through four points distinguished between: "strongly agree" (4) "agree" (3) "disagree" (2), and "strongly disagree" (1). A high self-esteem is indicated by a high score. Regarding the score, this can vary from 10 to 40 , based on the sum of the score given to the 10 sentences. A satisfactory self-esteem is defined as a score greater than or equal to 30 and unsatisfactory, with a score below 30 (Cogollo et al., 2015). Next, the Beck Anxiety Inventory (BAI), or Beck Anxiety Scale (BAS), created by Aaron Beck (Gandini, 2007), and validated in Brazil by Cunha in the year 2001 (Araújo et al., 2007), was applied. It is an instrument with a particularity, as it is ideal to be applied to psychiatric patients. It consists of a self-report scale proposed by Beck to discern the common symptoms of anxiety. The total score is the sum of the scores (0 to 63) with 21 items in total, using the following questions: "Not at all"; "Mildly (it did not bother me much)"; "Moderately (it was not pleasant at times)"; and "Severely (it bothered me a lot)". And the results can be: 0 to 9 - minimum anxiety; 10 to 16 - mild anxiety; 17 to 29 - moderate anxiety; and 30 to 63 - severe anxiety (Godoy et al., 2002). There were descriptive analyses of the demographic, clinical, obstetric and psychological variables, calculating the mean and standard deviation for continuous variables, and describing the absolute and relative frequencies for categorical variables. Later, $\mathrm{T}$ tests were performed (for continuous variables) and Chi-square test (for nominal variables) to compare the demographic and obstetric variables. To verify the correlation between self-esteem and anxiety, Pearson's chi-square test or the Fisher's exact test was used when the condition to use the Chi-square test was not verified. The margin of error used in the decision of the statistical tests was $5.0 \%$. The program used for data typing and statistical calculations was SPSS version 23.0, being presented as tables.

\section{RESULTS}

About the obstetric conditions of the pregnant women interviewed, in relation to the gestational age, more than half $(53.6 \%)$ of them were early preterm, followed by $31.2 \%$ late preterm, $14.3 \%$ early term and only one was term; regarding the number of pregnancies, the largest percentage corresponded to trigravida $(29.5 \%)$, the smallest, to multigravida $(20.5 \%)$ and primigravida and bigravida had $25.0 \%$ each; the majority $(71.4 \%)$ had not aborted and, among those who underwent abortion $(22.3 \%), 65.2 \%$ fell in unwanted/unplanned pregnancy. Among the reasons that led to hospitalization in high-risk sector, the most frequent were: single topical preterm pregnancy $(63.4 \%)$, Urinary Tract Infection (UTI) (25.9\%), Gestational Hypertension (21.4\%), Premature Labor (PL) (15.2\%), Gestational Diabetes Mellitus $(12.5 \%)$, single topical term pregnancy $(8.9 \%)$, pyelonephritis (8.9\%) and Premature Rupture of Membranes (PRM) (8.9\%). There may have happened more than one reason for hospitalization. Table 1 shows that most pregnant women $(72.3 \%)$ had poor self-esteem. Regarding anxiety, (39.3\%), $35.7 \%$ had mild to moderate anxiety, $16.1 \%$ moderate to severe and $8.9 \%$ severe anxiety. Table 2 reveals that the variability can be considered reduced on Rosenberg's scales and subscales, since the values of standard deviations are below $1 / 3$ of the corresponding means, whereas in the anxiety scale, the variability was high since the standard deviation was over half the mean value. 
Table 1: Self-esteem evaluation according to the Rosenberg's Self-Esteem Scale and anxiety evaluation according to Beck Anxiety Scale. Recife (PE), Brazil, April/June, 2016

\begin{tabular}{lcc}
\hline Variable & $N$ & $\%$ \\
\hline TOTAL & 112 & 100.0 \\
Self-esteem & & \\
Satisfactory & 31 & 27.7 \\
Unsatisfactory & 81 & 72.3 \\
Anxiety & & \\
No anxiety & 44 & 39.3 \\
Mild to moderate & 40 & 35.7 \\
Moderate to severe & 18 & 16.1 \\
Severe & 10 & 8.9 \\
\hline Source: Created by the authors. & &
\end{tabular}

Table 2: Statistics of self-esteem (Rosenberg) and anxiety (Beck) scales. Recife, Pernambuco (PE), Brazil, April/June, 2016.

\begin{tabular}{lccccc}
\hline Variable & Mean & SD & Median & P25 & P75 \\
\hline Rosenberg's self-esteem scale & 27.62 & 4.04 & 27.50 & 26.25 & 30.00 \\
Rosenberg's self-esteem positive sum & 16.10 & 2.75 & 16.00 & 14.25 & 18.00 \\
Rosenberg's self-esteem negative sum & 11.52 & 1.64 & 11.00 & 11.00 & 12.00 \\
Anxiety scale (Beck) sum & 13.21 & 9.51 & 12.00 & 5.00 & 18.75 \\
\hline
\end{tabular}

Source: Created by the authors.

Table 3: Relationship between self-esteem and sociodemographic data. Recife, Pernambuco (PE), Brazil, April/June, 2016

\begin{tabular}{|c|c|c|c|c|c|c|c|c|}
\hline \multirow{3}{*}{ Variable } & \multicolumn{4}{|c|}{ Self-esteem } & & & \multirow{3}{*}{ P-v-lue } & \multirow{3}{*}{ OR $(95 \% \mathrm{CI})$} \\
\hline & \multicolumn{2}{|c|}{ Unsatisfactory } & \multicolumn{2}{|c|}{ Satisfactory } & \multicolumn{2}{|c|}{ Total Group } & & \\
\hline & $\mathrm{N}$ & $\%$ & $\mathrm{~N}$ & $\%$ & $\mathrm{~N}$ & $\%$ & & \\
\hline Age Group & & & & & & & $\mathrm{p}^{(1)}=0.662$ & \\
\hline $18-20$ & 10 & 58.8 & 7 & 41.2 & 17 & 100.0 & & 1.00 \\
\hline $21-25$ & 31 & 72.1 & 12 & 27.9 & 43 & 100.0 & & $1.81(0.56-5.85)$ \\
\hline $26-30$ & 17 & 81.0 & 4 & 19.0 & 21 & 100.0 & & $2.98(0.69-12.76)$ \\
\hline $31-35$ & 8 & 72.7 & 3 & 27.3 & 11 & 100.0 & & $1.87(0.36-9.63)$ \\
\hline 36 or more & 15 & 75.0 & 5 & 25.0 & 20 & 100.0 & & $2.10(0.52-8.51)$ \\
\hline Marital Status & & & & & & & $\mathrm{p}^{(2)}=0.702$ & \\
\hline Unmarried & 23 & 71.9 & 9 & 28.1 & 32 & 100.0 & & ** \\
\hline Married & 26 & 65.0 & 14 & 35.0 & 40 & 100.0 & & \\
\hline Stable union / living together & 30 & 78.9 & 8 & 21.1 & 38 & 100.0 & & \\
\hline Widow & 1 & 100.0 & - & - & 1 & 100.0 & & \\
\hline Others & 1 & 100.0 & - & - & 1 & 100.0 & & \\
\hline Schooling & & & & & & & $\mathrm{p}^{(1)}=0.004^{*}$ & \\
\hline Up to incomplete elementary education & 24 & 96.0 & 1 & 4.0 & 25 & 100.0 & & ** \\
\hline Elementary education & 21 & 75.0 & 7 & 25.0 & 28 & 100.0 & & \\
\hline Secondary / higher education & 36 & 61.0 & 23 & 39.0 & 59 & 100.0 & & \\
\hline Family income (minimum wage) & & & & & & & $\mathrm{p}^{(2)}=0.306$ & \\
\hline Below one & 13 & 72.2 & 5 & 27.8 & 18 & 100.0 & & 1.00 \\
\hline One & 42 & 79.2 & 11 & 20.8 & 53 & 100.0 & & $1.47(0.43-5.00)$ \\
\hline $1-2$ & 20 & 60.6 & 13 & 39.4 & 33 & 100.0 & & $0.59(0.17-2.06)$ \\
\hline Over 2 & 6 & 75.0 & 2 & 25.0 & 8 & 100.0 & & $1.15(0.17-7.74)$ \\
\hline Occupation & & & & & & & $\mathrm{p}^{(1)}=0.068$ & \\
\hline Yes & 59 & 77.6 & 17 & 22.4 & 76 & 100.0 & & $2.21(0.93-5.22)$ \\
\hline No & 22 & 61.1 & 14 & 38.9 & 36 & 100.0 & & 1.00 \\
\hline Housing & & & & & & & $\mathrm{p}^{(1)}=0.798$ & \\
\hline Rural zone & 14 & 70.0 & 6 & 30.0 & 20 & 100.0 & & 1.00 \\
\hline Urban zone & 67 & 72.8 & 25 & 27.2 & 92 & 100.0 & & $1.15(0.40-3.32)$ \\
\hline Religion & & & & & & & $\mathrm{p}^{(1)}=0.874$ & \\
\hline Catholic & 29 & 74.4 & 10 & 25.6 & 39 & 100.0 & & 1.00 \\
\hline Evangelical & 40 & 70.2 & 17 & 29.8 & 57 & 100.0 & & $0.81(0.33-2.03)$ \\
\hline No religion & 12 & 75.0 & 4 & 25.0 & 16 & 100.0 & & $1.03(0.27-3.95)$ \\
\hline TOTAL & 81 & 72.3 & 31 & 27.7 & 112 & 100.0 & & \\
\hline
\end{tabular}

Source: Created by the authors. (*) Significant association at 5\%. / (1) Through Pearson’s Chi-Square Test. / (2) Through Fisher’s Exact Test.

Table 3 presents the association between sociodemographic variables and self-esteem. Schooling was the only variable with significant association with self-esteem $(\mathrm{p}=0.004)$, uncovering that poor self-esteem reduces the measure as the degree of schooling increases. Furthermore, $66.5 \%$ of the interviewees are from 18 to 30 years and women aged 26 to 30 years tend to show greater dissatisfaction. The age of pregnant women in this sample was not significant in the definition of scores of self-esteem.
Table 4 unveils the association between anxiety scale and sociodemographic variables. According to the analyzed data, religion was the only variable with a significant association with the anxiety scale $(\mathrm{p}=0.04)$ and, for that variable, the percentage with anxiety was higher among those who had no religion $(87.5 \%$ ), and ranged from $52.6 \%$ to $61.5 \%$ among evangelical and catholic women. Table 5 shows the association between the degrees of anxiety and level of self-esteem. There was no significant association. 
Table 4: Relationship between anxiety and sociodemographic data. Recife, Pernambuco (PE), Brazil, April/June, 2016

\begin{tabular}{|c|c|c|c|c|c|c|c|c|}
\hline \multirow{3}{*}{ Variable } & \multicolumn{4}{|c|}{ Anxiety } & \multirow{2}{*}{\multicolumn{2}{|c|}{ Total group }} & \multirow{3}{*}{ p-value } & \multirow{3}{*}{ OR $(95 \% \mathrm{CI})$} \\
\hline & \multicolumn{2}{|c|}{ With } & \multicolumn{2}{|c|}{ Without } & & & & \\
\hline & $\mathrm{N}$ & $\%$ & $\mathrm{~N}$ & $\%$ & $\mathrm{~N}$ & $\%$ & & \\
\hline Age Group & & & & & & & $\mathrm{p}^{(1)}=0.234$ & \\
\hline $18-20$ & 12 & 70.6 & 5 & 29.4 & 17 & 100.0 & & $1.60(0.40-6.32)$ \\
\hline $21-25$ & 26 & 60.5 & 17 & 39.5 & 43 & 100.0 & & $1.02(0.34-3.01)$ \\
\hline $26-30$ & 9 & 42.9 & 12 & 57.1 & 21 & 100.0 & & $0.50(0.14-1.73)$ \\
\hline $31-35$ & 9 & 81.8 & 2 & 18.2 & 11 & 100.0 & & $3.00(0.51-17.68)$ \\
\hline 36 or more & 12 & 60.0 & 8 & 40.0 & 20 & 100.0 & & 1.00 \\
\hline Marital Status & & & & & & & $\mathrm{p}^{(2)}=0.345$ & \\
\hline Unmarried & 20 & 62.5 & 12 & 37.5 & 32 & 100.0 & & $* *$ \\
\hline Married & 21 & 52.5 & 19 & 47.5 & 40 & 100.0 & & \\
\hline Stable union / living together & 26 & 68.4 & 12 & 31.6 & 38 & 100.0 & & \\
\hline Widow & - & - & 1 & 100.0 & 1 & 100.0 & & \\
\hline Others & 1 & 100.0 & - & - & 1 & 100.0 & & \\
\hline Schooling & & & & & & & $\mathrm{p}^{(1)}=0.169$ & \\
\hline Up to incomplete elementary education & 17 & 68.0 & 8 & 32.0 & 25 & 100.0 & & $1.92(0.72-5.13)$ \\
\hline Elementary education & 20 & 71.4 & 8 & 28.6 & 28 & 100.0 & & $2.26(0.86-5.93)$ \\
\hline Secondary / higher education & 31 & 52.5 & 28 & 47.5 & 59 & 100.0 & & 1.00 \\
\hline Family income (minimum wage) & & & & & & & $\mathrm{p}^{(2)}=0.189$ & \\
\hline Below one & 13 & 72.2 & 5 & 27.8 & 18 & 100.0 & & $1.56(027-9.11)$ \\
\hline One & 35 & 66.0 & 18 & 34.0 & 53 & 100.0 & & $1.17(0.25-5.44)$ \\
\hline $1-2$ & 15 & 45.5 & 18 & 54.5 & 33 & 100.0 & & $0.50(0.10-2.44)$ \\
\hline Over 2 & 5 & 62.5 & 3 & 37.5 & 8 & 100.0 & & 1.00 \\
\hline Occupation & & & & & & & $\mathrm{p}^{(1)}=0.193$ & \\
\hline Yes & 43 & 56.6 & 33 & 43.4 & 76 & 100.0 & & 1.00 \\
\hline No & 25 & 69.4 & 11 & 30.6 & 36 & 100.0 & & $1.74(0.75-4.05)$ \\
\hline Housing & & & & & & & $\mathrm{p}^{(1)}=0.665$ & \\
\hline Rural zone & 13 & 65.0 & 7 & 35.0 & 20 & 100.0 & & $1.25(0.46-3.43)$ \\
\hline Urban zone & 55 & 59.8 & 37 & 40.2 & 92 & 100.0 & & 1.00 \\
\hline Religion & & & & & & & $\mathrm{p}^{(1)}=0.041^{*}$ & \\
\hline Catholic & 24 & 61.5 & 15 & 38.5 & 39 & 100.0 & & 1.00 \\
\hline Evangelical & 30 & 52.6 & 27 & 47.4 & 57 & 100.0 & & $0.69(0.30-1.59)$ \\
\hline No religion & 14 & 87.5 & 2 & 12.5 & 16 & 100.0 & & $4.38(0.87-22.02)$ \\
\hline TOTAL & 68 & 60.7 & 44 & 39.3 & 112 & 100.0 & & \\
\hline
\end{tabular}

Table 5: Relationship between types of anxiety according to Beck scale and level of self-esteem according to Rosenberg's scale. Recife, Pernambuco (PE), Brazil, April/June, 2016

\begin{tabular}{|c|c|c|c|c|c|c|c|}
\hline \multicolumn{8}{|c|}{ Self-esteem } \\
\hline Beck Anxiety & \multicolumn{2}{|c|}{ Unsatisfactory } & \multicolumn{2}{|c|}{ Satisfactory } & \multicolumn{2}{|c|}{ Total group } & p-value \\
\hline & $\mathrm{N}$ & $\%$ & $\mathrm{~N}$ & $\%$ & $\mathrm{~N}$ & $\%$ & \\
\hline Severe & 9 & 11.1 & 1 & 3.2 & 10 & 8.9 & $\mathrm{p}^{(1)}=0.503$ \\
\hline Moderate to severe & 13 & 16.0 & 5 & 16.1 & 18 & 16.1 & \\
\hline Mild to moderate & 30 & 37.0 & 10 & 32.3 & 40 & 35.7 & \\
\hline No anxiety & 29 & 35.8 & 15 & 48.4 & 44 & 39.3 & \\
\hline TOTAL & 81 & 100.0 & 31 & 100.0 & 112 & 100.0 & \\
\hline
\end{tabular}

Source: Created by the authors. (1) Through Fisher's Exact Test.

\section{DISCUSSION}

Pregnancy is a moment that results in changes in the physical, social and emotional aspects of the woman, and the decreased self-esteem is associated with several factors, such as selfperception, process of adaptation to the body, hormonal changes, in the domestic routine, in the relationship with the spouse and family. The occurrence of implications in selfesteem can affect the proper development of the fetus and, later, the life of the mother and the child (Silva et al., 2010). Santos et al., (2015), emphasize that high-risk pregnancy constitutes a disturbing experience because of its risks for the child and mother and their possible psychological and physical impairments. In this sense, when observing the levels of anxiety and low self-esteem in high-risk pregnant women, $60.7 \%$ of them present with some level of anxiety and $72.3 \%$ have poor self-esteem. In this study, $65.2 \%$ of the interviewees reported experiencing an unwanted/unplanned pregnancy. According to Silva et al., (2017), the non-occurrence of family planning allied to the propensity to triggering emotional disorders and other associated factors, can be triggering factors for the development of mental disorders in pregnant women, generating major impacts on the mental health of those women. In relation to schooling, Santos et al., (2015), affirm that there is an unsatisfactory relationship between low schooling and self-esteem. In this study, among 25 women who have not completed elementary education, $96 \%$ have poor self-esteem. Among those who have completed elementary education, only $25 \%$ are satisfied with their self-esteem and, among 36 women who attended high school and college, $61 \%$ are not satisfied with their self-esteem. Moreover, according to Santos et al. (2016), the pregnant women's family income can directly influence their self-esteem. According to the findings of this research, among all women with unsatisfactory selfesteem, $51.85 \%$ of them survive with one monthly minimum wage. Considering occupation variable, Maçola et al., (2010), bring, in their research, that there was no significant relationship between having or not an employment and (un)satisfactory self-esteem. However, the need to talk about the activities performed demonstrated that the women who worked out-of-home had a certain apprehension about the new 
life style and triple working hours, whereas the women who worked as "housekeepers" felt less apprehensive. In the present study, $77.6 \%$ of employed women and $61.1 \%$ of those unemployed feel dissatisfied with the self-esteem, which agrees with the previous survey and may suggest that unsatisfactory self-esteem is beyond having or not an occupation. Comparing the pregnant women who had a religion and those who had not, the non-practitioners have a higher rate of unsatisfactory self-esteem. Joshua et al. (2008), in their studies, showed that the proportion of pregnant women with no religion obtained a self-esteem significantly less satisfactory. In studies involving assistance to the pregnant woman's health, the biopsychological disorders are recurrent throughout the pregnancy-puerperium period, including anxiety. Thus, the changes in the emotional spheres should receive due attention, as well as clinical manifestations, once they endanger the pregnant woman's health and quality of life (Medeiros, 2016). Araújo et al., (2007), show that most of their interviewees had low income, constituting potential risk factors for developing anxiety in pregnancy, and add that the family income may have a negative influence on the pregnancy, being a great stress factor. Such analysis is highlighted in the findings of the present study, which show that $72.2 \%$ of the respondents received less than one minimum wage and developed anxiety in pregnancy. In relation to marital status, in the present study, $68.4 \%$ of the interviewees have a stable union or are married and stated having developed anxious symptoms in pregnancy. Silva et al. (2015) confirm this finding, since they evidenced a greater frequency of pregnant women married or living with the partner with anxious symptoms $(82.8 \%)$. As for the variable occupation, the same authors reveal that most pregnant women exercised labor activity (49.3\%), which differs from the findings of this study, in which $69.4 \%$ of the interviewees reported having no occupation. The occupation, as well as family income, can provide perception of balance for the pregnant woman, since the existence of a wage decreases the concerns regarding this period of preparation for the birth of the child (Silva et al., 2015). Low self-esteem, history of psychiatric diseases, postpartum depression, anxiety during pregnancy, stress, expectations related to motherhood, rejection of pregnancy, the aid provided during delivery, feeling of inability to take care of the child and other factors reveal themselves as the main factors that affect the quality of life of the mother, as well as of the newborn (Gawron et al., 2015). Table 05 unveils that the correlation of the applied scales assists in understanding the incidence of anxiety levels and its implications in women's self-esteem. In their studies, Silva et al., (2010), show that the self-esteem in pregnant women is associated with changes in their mental status, and affirm that pregnant women with lower self-esteem had a higher probability of developing mental disorders, but the studies that address this issue are still scarce. Notably, the aim of this study was to compare the results of the assessment of anxiety (Beck) with the results of self-esteem (Rosenberg), revealing a statistically significant correlation between the two scales evaluated, since the $p$ value is 0.503 , i.e., $p>0.5$. Since there was no significance, there was no possibility of proving, through scientific researches, studies that resemble this finding.

\section{Conclusion}

Self-esteem and anxiety are conditions that must be preserved during pregnancy. The present study unveiled that sociodemographic and obstetric factors can potentially interfere with the quality of pregnancy and the lives of those women. Self-esteem is related to the self-acceptance or selfrejection, and this set of perceptions of oneself makes these pregnant women to know themselves and know how to deal with new situations, as is the case of pregnancy, even with the influences of culture, religion, beliefs, and/or experiences. Self-esteem favors the mental, emotional and physical health of pregnant women, as well as contributes to interpersonal relationships and acceptance of the pregnancy, since this psychological imbalance may cause serious health problems, including anxiety. Nevertheless, the present study could not make a significant relationship between anxiety and selfesteem. This suggests the separate screening of signs and symptoms of each one, based on the socioeconomic, cultural and epidemiological profile of the studied population, in order to promote actions of health promotion and disease prevention, through activities that raise awareness and carry information to women about the studied topics. A qualified assistance in Basic Care (BC), through the Family Health Strategy (FHS), focusing on care longitudinality and comprehensiveness, since before the pre-natal consultations, until the puerperium, is crucial to approach and reach the public of study and the strategies proposed in this study. Furthermore, the need for monitoring by the multiprofessional team, its constant updating about its target audience, in possession of continued education about the studied topics, is evident for pregnant women a healthier experience pregnancy, more humane, satisfactory and with a greater reduction of possible damage.

\section{REFERENCES}

Araújo RB, Oliveira MS, Moraes JFD, Pedroso RS, Port F, Castro MGT 2007. Validation of the Brazilian version of the Questionnaire of Smoking Urges-Brief. Rev Psiquiatr Clín. 344):166-75.

Castro RTA, Anderman CP, Glover V, O’Connor TG, Ehlert U, Kammerer M 2017. Associated symptoms of depression: patterns of change during pregnancy. Arch Womens Ment Health [Internet]. 2017 [cited 2019 June 15] 20:123-128. Doi: 10.1007/s00737-016-0685-6.

Cogollo, Z, Campo-Arias, A, \& Herazo, E 2015. Escala de Rosenberg para autoestima: consistencia interna y dimensionalidad en estudiantes de Cartagena, Colombia. Psychologia: Avances de la Disciplina. 92):61-71.

Gandini RC, Martins MCF, Ribeiro MP, Santos DTG 2007. Beck Depression Inventory - BDI: factorial validation for women with cancer. PsicoUSF 121):23-31

Godoy DV, Godoy RF 2002. Reduction in anxiety and depression levels in patients with chronic obstructive pulmonary disease COPD) who participated in a pulmonary rehabilitation program. J Pneumol. 283):120-4.

Goyatá SLT, Avelino CCV, Santos SVM, Junior DIS, Gurge MDSL, Terra FS 2016. Effects from acupuncture in treating anxiety: integrative review. Rev Bras Enferm. 693):564-71.

Osorio-Castaño JH, Carvajal-Carrascal G, Rodríguez-Gázquez M 2017. Preparation for Motherhood during Pregnancy: a Concept Analysis. Invest Educ Enferm. 353):295-305.

Parreira BDM, Goulart BF, Haas VJ, Silva SR, Monteiro JCS, Gomes-Sponholz FA 2017. Common mental disorder and associated factors: study with women from a rural area. Rev Esc Enferm USP. 51:e03225.

Silva RA, Ores LC, Mondin TC, Rizzo RN, Moraes IGS, Jansen, K, Pinheiro RT 2010. Common mental disorders 
and self-esteem in pregnancy: prevalence and associated factors. Cad. Saúde Pública. 269):1832-38.

Santos AB, Santos KEP, Monteiro GTR, Prado PR, Amaral TLM 2015. Self-esteem and quality of life and a series of pregnant women attended in public health network. Cogitare enferm. 202);392-400.

Silva MMJ, Nogueira DA, Clapis MJ, Leite EPRC 2017. Anxiety in pregnancy: prevalence and associated factors. Rev Esc Enferm USP. 51:e03253.

Santos AB, Santos KEP, Monteiro GTR, Prado PR, Amaral TLM 2015. Autoestima e qualidade de vida de uma série de gestantes atendidas em rede pública de saúde. Cogitare Enferm. 202):392-400.

Santos AB, Santos KEP, Monteiro GTR, Prado PR, Amaral TLM 2015. Autoestima e qualidade de vida de uma série de gestantes atendidas em rede pública de saúde. Cogitare Enferm. 202):392-400.
Joshua RM, Robert EM, Janice B, Roumen V, Freda B 2008. Do Antenatal Religious and Spiritual Factors Impact the Risk of Postpartum Depressive Symptoms?. Journal of Women's Health [internet]. 175.

Medeiros AL, Santos SR, Cabral RWL, Silva JPG, Nascimento NM 2016. Evaluating nursing diagnoses and interventions in labor and in gestation at risk. Rev Gaúcha de Enferm. 373):1-9.

Silva MMJ, Leite EPRC, Nogueira DA, Clapis MJ 2015. Anxiety and depression in pregnancy: characterization of pregnant women who performed prenatal care in public health units. Rev enferm UFPE on line;9:9027-37.

Gawron MFG, Swiehcz LGS, Godoi ATM, Oselame GB 2015. Factors triggering postpartum depression: narrative review. Health and Development Magazine. 84):52-9. 